\title{
Preparing for One-on-One Qualitative Interviews: Logistics ${ }^{1}$
}

\author{
Kathryn A. Stofer ${ }^{2}$
}

This document provides practical tips for beginning researchers and Extension agents in the logistics of preparing for, conducting, and wrapping up interviews for qualitative research and evaluation. Tips include obtaining research approval, arranging participant incentive payments, selecting and setting up the interview location, and ensuring proper operation of data collection devices and data storage. These tips are designed to help the data collection go smoothly by attending to details expediently, allowing the interviewer to concentrate during the interview on collecting meaningful, high-quality data. This document is designed to accompany AEC675, Preparing for One-on-One Qualitative Interviews (http://edis.ifas.ufl.edu/wc338).

\section{Preparing for Data Collection}

To conduct interviews effectively, researchers or evaluators will need to complete several steps in preparation before and after the interview to ensure the best data collection.

\section{Obtaining Research Approval}

For interviews, best practices include obtaining Institutional Review Board (IRB) approval if available. IRB offices oversee the ethical treatment of participants at academic and other major institutions that conduct research with humans. They are most strict in their guidelines for projects that involve medical interventions or use questions on medical history and other highly sensitive personal data. Additionally, studies that recruit participants from sensitive or vulnerable populations, such as minors, pregnant women, and those who speak another language, are strictly reviewed. For University of Florida IRB regulations and procedures, please see http://irb.ufl.edu/.

For interview studies, the IRB generally wants to approve the interview guide and may require a more or less rigid structure depending on the nature of the subject matter. IRB review and approval can take weeks or months, so best practice suggests beginning the process as soon as possible. The IRB will also approve participant recruitment materials, including flyers, email or social media post language, and telephone scripts. You may be asked to revise certain areas of your study design to clarify and/or meet regulations. IRB may also be required if you want to offer compensation to your research participants for their time spent assisting with the study. For guidelines on how much to compensate, see discussion on four models of offering payment and their respective tradeoffs (Williams \& Walter, 2015).

\section{Piloting Your Interview Guide}

After obtaining IRB approval, it is best practice to pilot-test your guide with at least a few participants from your population or people who are very similar (e.g., advanced graduate students if you want to interview faculty, or students from one high school if you want to interview high school students from a different school). Piloting the interview allows you to:

- Ensure you have all of your necessary materials gathered, such as an audio recorder and batteries, IRB consent

1. This document is AEC676, one of a series of the Department of Agricultural Education and Communication, UF/IFAS Extension. Original publication date August 2019. Visit the EDIS website at https://edis.ifas.ufl.edu for the currently supported version of this publication.

2. Kathryn A. Stofer, research assistant professor, Department of Agricultural Education and Communication; UF/IFAS Extension, Gainesville, FL 32611

The Institute of Food and Agricultural Sciences (IFAS) is an Equal Opportunity Institution authorized to provide research, educational information and other services only to individuals and institutions that function with non-discrimination with respect to race, creed, color, religion, age, disability, sex, sexual orientation, marital status, national origin, political opinions or affiliations. For more information on obtaining other UF/IFAS Extension publications, contact your county's UF/IFAS Extension office. U.S. Department of Agriculture, UF/IFAS Extension Service, University of Florida, IFAS, Florida A \& M University Cooperative Extension Program, and Boards of County Commissioners Cooperating. Nick T. Place, dean for UF/IFAS Extension. 
forms, and note-taking devices. See section on creating a checklist, below.

- Ensure your questions are clear and that you are getting the types of answers you expect.

- Ensure your questions cover all the topics that you wish to cover and do not have redundancies.

- Get a feel for how long the interview will take.

- Practice your interviewing skills.

- Test your audio recorders for audio clarity, length of battery life, and recording space.

- Test the suitability of the space in which you will conduct the interview; that is, to ensure both audio and visual distractions are minimized.

Piloting may not be possible with very sensitive populations, very small populations, or populations that are difficult to recruit. In those cases, reviewing the guide with collaborators or outside experts can substitute. However, pilot participants may also be included in your final data set with proper approval from IRB if the questions or data collected do not change significantly after the pilot, making it feasible in some cases to pilot even with limited or vulnerable populations.

After piloting, resolve the issues with your guide, and submit revisions to IRB, if necessary. Also, do not be afraid to go through more than one round of piloting. However, do be aware that the time it takes to pilot will also increase your timeline. Consider this if you need to collect interviews within a defined time frame for any reason, such as at an event or conference.

\section{Preparing for the Interview}

Once you have set your interview guide but before you recruit participants, find a location that will be distractionfree. If you have a private office and it is easily accessible, that will be most flexible for scheduling. However, consider when your participants will be available and how they will get to your location. Reserving a conference room at a public library may be a compromise that works for both you and your participants. For a location that is not your own space, you may want to create a sign to hang on the door to deter people from entering during an ongoing interview. Be sure to share directions with participants who are not familiar with the area in which you are conducting the interview. Drafting a template email for confirmation will make this process quicker and minimize the chances you omit necessary information. Always include both an email and, especially for the day of the interview, a phone number where participants can reach you. Consider a free forwarding service such as a Google Voice number if you are concerned about giving out your own number. Setting aside adequate time to conduct the interview will allow you and the participant not to feel rushed and will allow for delays from traffic or transportation slow-downs or confusion about directions (Telg, 2015).

Finally, creating a checklist of items to bring and steps to complete during the interview will help you minimize distractions. A checklist can help you offload small details, allowing you to focus on the work of the interview itself. The Appendix (page 4) includes a checklist created for a study that involved showing participants images on a computer as stimuli.

\section{Immediately Prior to an Interview: Set-Up}

Make sure you have all these materials ready to go well in advance of the participant's arrival.

- Audio or video recorder

- Ensure sufficient space to record the interview

- Power for recorder (if a phone or other rechargeable device, be sure to charge well in advance)

- Backup power, especially if battery-powered

- Backup recorder

- Ensure sufficient space to record the interview

- Power for backup recorder (if a phone or other rechargeable device, be sure to charge well in advance)

- Backup power, especially if battery-powered

- Sign for door indicating "Interview in Progress"

- Tape or other means to hang sign

- Study materials: for example, computer with images for prompting or video presentation, set up and running properly; or a set of prototype designs on paper for participants to review

- Consent form with additional copy for participant

- Pen

- Notebook for notes (or laptop or tablet with enough power and file space)

- Pen or pencil

- Interview guide

- Receipt for incentive

- Incentive

- Payment log

- Water for you and/or the participant 


\section{During the Interview}

If you are prepared, hopefully you will only need to concentrate on the conversation and note-taking during the interview.

- Obtain informed consent from the participant as approved by the IRB.

- Make sure to start the recorders with acknowledgement from the participant.

- If the interview is long, allow the participant to take breaks if possible. What participants consider long will vary with age and other demographic characteristics.

- Take notes as you go, in case of complete failure of all your recorders or in case the participant has not consented to be recorded. Notes also will help you stay focused on what the participant is saying and jot down ideas to be probed and to return to in your data analysis.

\section{After the Interview}

Congratulations! You have collected an important set of data. Now you must be sure you handle it properly to protect your participant and to maintain data integrity (that is, to ensure it does not get deleted or irretrievably corrupted).

Before your participant leaves, give them the incentive if there is one, and if so, have them sign a receipt or payment log. Ensure you have their signed consent form and have signed it yourself with the correct date. Offer them a copy if they have not yet taken one.

Immediately after the participant leaves, or as soon thereafter as is reasonably possible, write down your overall thoughts on the interview, including ideas that may be emerging from multiple participants. Review your notes and clarify any areas that you abbreviated during the interview. It is a good idea to schedule 15-20 minutes immediately after each interview to allow for this. Check to ensure your recordings were completed, and if they were not, write down as much detail as you can remember from the interviews, because this is now your only record for this participant. Recreate quotes if you can, but be sure to check with this participant before using any quotes to ensure accuracy.

Assuming your recordings worked, back up your data onto your computer and, ideally, an automatically backed-up system such as TimeMachine for Mac, Dropbox through UF's subscription, or IFAS-managed hard drives.
Record your payments in the appropriate system (paper log, online, or computer file). If you are using prepaid gift cards from UF, make sure the gift card is loaded, because you must match the participant's name and address to the gift card number to ensure they can activate and use the card. File consent forms and receipts in a folder in a locked file cabinet, making digital copies as a backup if possible, even if you take photos of the forms with a smartphone.

Next you are ready to transcribe, analyze, and report your data.

\section{Summary}

Collecting qualitative data can involve many steps. This document is intended to clarify the various considerations a researcher or evaluator should account for. It also provides example checklists to enable some of the smaller, lessthought-intensive but crucial steps to be completed without major time or energy investments. Qualitative data can provide rich evidence for the success of your programs or background for developing new initiatives.

\section{References}

Telg, R. (2015). Conducting interviews for news stories. AEC532. Gainesville: University of Florida Institute of Food and Agricultural Sciences. https://edis.ifas.ufl.edu/wc194

Williams, E. P., \& Walter, J. K. (2015). When does the amount we pay research participants become "undue influence"? AMA Journal of Ethics, 17(12), 1116-1121. https:// doi.org/10.1001/journalofethics.2015.17.12.ecas2-1512 


\section{Appendix}

Below is an informal example study checklist from the author's dissertation research involving eye-tracking. Text has been copied as-is for effect.

Before:

Go to bathroom

Breath mint

laptop w/presentation software, power cord

screen for subject

IRB Consent form - copy for me AND them

blinds drawn

Shawn's phone unplugged

water for subjects

extra batteries

wireless internet/ethernet cable

gift cards and receipt

pens/pencils

notes

camera

voice recorder

interview questions

During:

Door sign

Consent (give them copy)

Cell phones off

Start video/audio

Color vision screening

Experts - Background question (Expert visualization)

Draw number from appropriate group (vis/nonvis/under-

grad)

Experiment

Background questions

After:

Stop video/audio

Gift card

Receipt

Consent form copy

Let subject go

Analytic notes

Record gift card numbers

Plug in shawn's phone
DATA:

Scan notes

Backup laptop (eyetracker)

Upload movies, compress

Upload audio, break up into 5 min chunks, upload to Mechanical turk 